\title{
RUSSIAN INDUSTRIAL SECTOR IN SEPTEMBER 2013
}

\author{
S.Tsukhlo
}

According to the Gaidar Institute's business survey data ${ }^{1}$, the September performance scoreb proved pessimistic rather than otherwise. The dynamics of demand and output underwent no fundamental change which disccouraged enterprises and resulted in a lower satisfaction with demand and an increase in the inventory excess rate. That said, the industrial sector kept raising prices, which would hardly fuel demand. A continuous exodus of employees from enterprises leads to labor force shortages even in the conditions of stagnation. Corporate investment plans signal a further cutting back on investment in production.

\section{Demand for Industrial Produce}

The September dynamic of demand underwent no fundamental change. Both initial and cleared-of-seasonality data displayed a slight acceleration of decline in sales, which interrupted a positive (for the current conditions) trend towards slowdown of the demand decline rate, which would manifested itself between July and August (Fig. 1). The September balance of assessments (satisfaction rate) of current sales plummeted nearly to zero after hitting twelve-month highs back in August. The industrial sector proved unhappy with results of $\mathrm{Q} 3$ and is likely to keep looking for volumes of production and output which would be normal for conditions of a continuous stagnation.

The initial projections of demand have been in a steady (except for a natural, since this year, intermezzo in May) decline since the beginning of the year (after they sky-rocketed in January from -19 to +28 points) and had lost 30 points by September. However, their formal clearing of seasonality displays their relative stability in the range between $+2 . .+11$ points and improvement up to +7 points in the month in question.

\section{Inventories}

In September, inventories estimates likewise underwent a negative adjustment (Fig. 2). Weak demand, an increasing dissatisfaction with its volumes coupled with the unpredictability of even the nearest prospects of Russia's economy forced enterprises to once again radically revise their inventories estimates. While they improved by 10 points at once in July and added yet another two points in August, in September their balance plunged 6 points, thus having them lose a half

\footnotetext{
1 Surveys of managers of industrial enterprises are carried out by the Gaidar Institute in accordance with the European harmonized methods on a monthly basis from September 1992 and cover the entire territory of the Russian Federation. The size of the panel includes about 1,100 enterprises with workforce exceeding $15 \%$ of workers employed in industry. The panel is shifted towards large enterprises by each sub-industry. The return of queries amounts to $65-70 \%$.
}

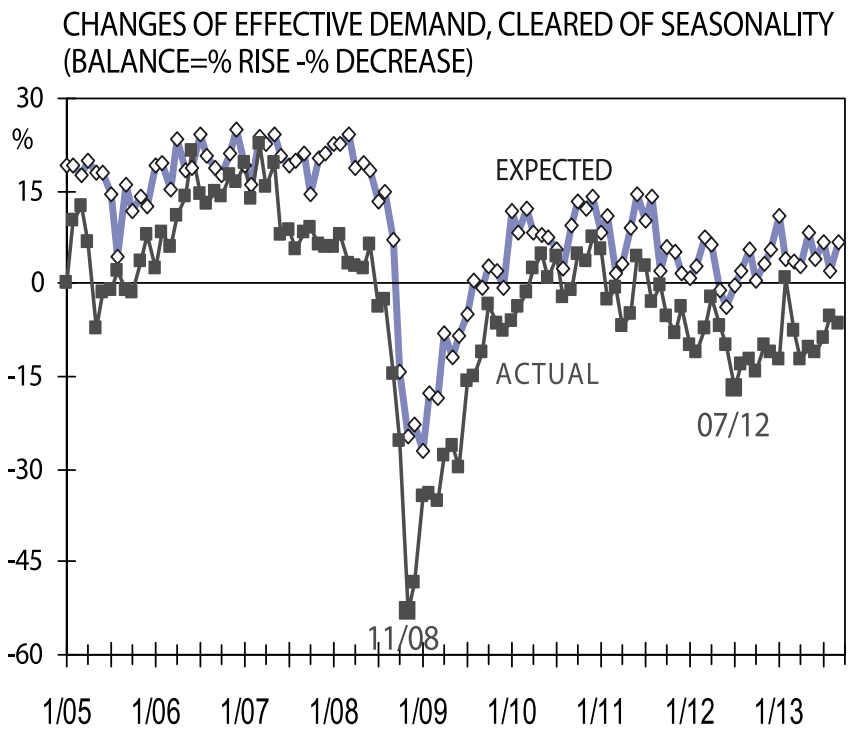

Fig. 1

$\%$

BALANCE OF ESTIMATES OF INVENTORIES

(BALANCE $=\%$ OF ABOVE THE NORM - \% OF BELOW THE NORM)

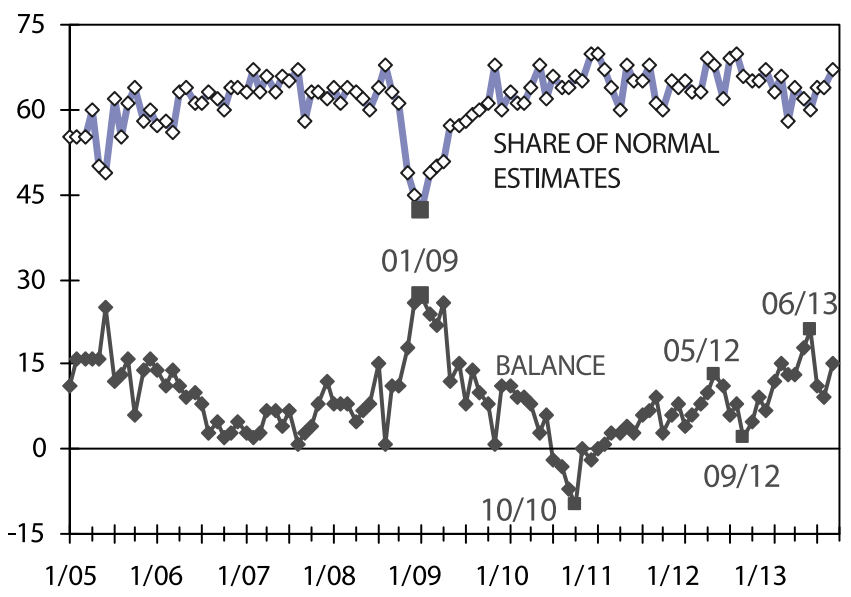

Fig. 2 
of their previous achievements. Meanwhile, the June results have remained so far the worst ones over the period after the peak of the crisis was over, which is quite notable, for according to data of the IET's (anti-) crisis monitoring, the domestic industrial sector gives importance to minimization of inventories while gearing up for a second wave of the crisis - enterprises rank this move second or third in the overall rating of anti-crisis measures, and as many as $28 \%$ of plants currently, in Q3, practices it.

\section{Output}

Like demand, the industrial output in September did not see neither clearly positive changes, nor certainly negative ones (Fig. 3). Initial data displayed a drop by a minimum number of balance points, while cleared of seasonality, the data evidenced an acceleration of the rate of rise in output. Consequently, the data for Q3 showed a symbolic 3-point improvement of the indicator. The output plans display an amorphous dynamic in 2013 and have remained in the range between $+12 . .+18$ balance points from the beginning of the year.

\section{Producer Prices}

Having started in August 2013, the producer price rise in the industrial sector continued into September, with the rate of change remaining the same. Last year, the $\mathrm{H} 2$ price rise started in July, but nearly faded away in August, and in November 2012, there was registered an absolute price downfall (Fig. 4). For the time being, the price rise proves most intense in the forestry, food processing, and the ferrous metallurgy. None of the industries reported an absolute decline in prices over August and September, albeit prices of machine-engineering and chemical plants, as well as construction enterprises, rose slightly above the zero mark.

The price rally in $\mathrm{H} 22013$ is fueled by plans of their change. In September, the balance of expectations climbed up by 7 points, which signals corporations' intent to continue raising prices, or, at least, to keep the price rise in place through the end of the year. Nothing like this was noted back in 2012 and 2011 - at the time, the November and December surveys typically registered forecasts of a minimum price rise.

\section{The Actual Dynamic and Plans of Lay-offs}

According to the survey data, the exodus of labor force was still underway. In September, the balance (intensity) of the change in the actual number of employees at enterprises remained at a level of the three summer months and accounted for -7 points (Fig. 5). In May 2013, it sank to до -13 points, while in January - to -26 . So, it is the months with the greatest number of
\% CHANGES IN VOLUMES OF OUTPUT, CLEARED OF SEASONALITY
(BALANCE $=\%$ RISE $-\%$ DECREASE)

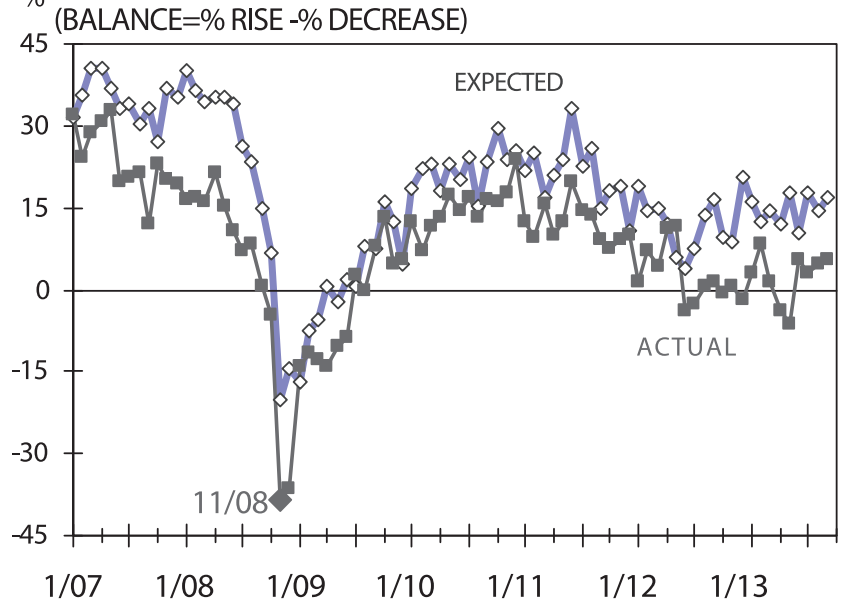

Fig. 3

\section{CHANGES IN PRODUCER PRICES \\ $\%$ (BALANCE $=\%$ RISE -\% DECREASE)}

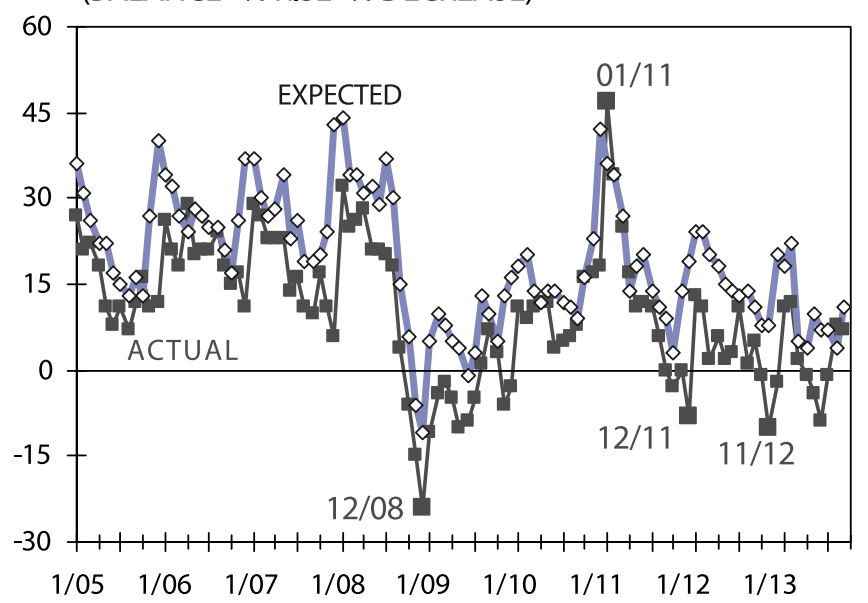

Fig. 4

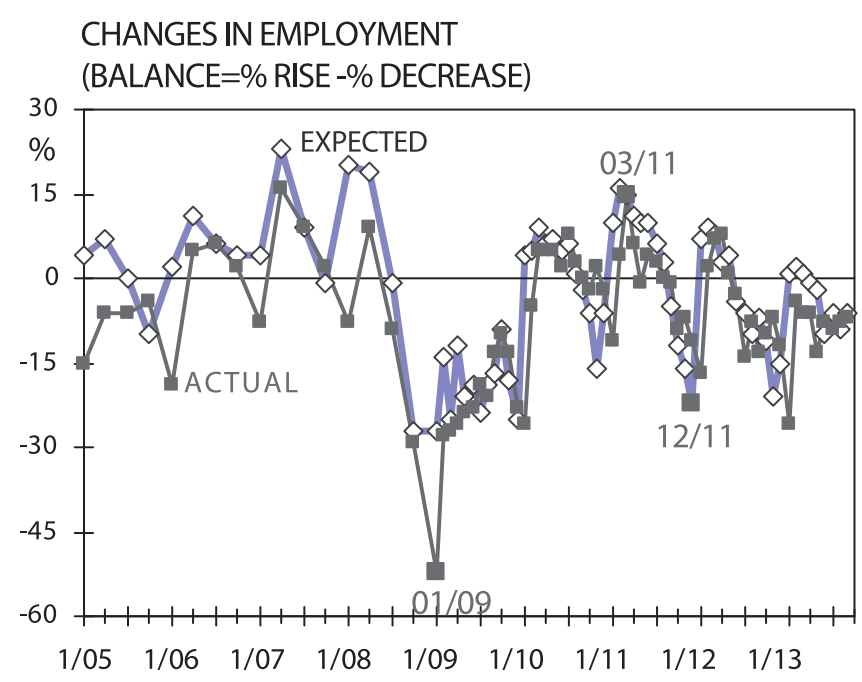

Fig. 5 
idle days when the industrial sector typically loses the greatest number of work force. Notably, the domestic industrial sector has seen a steady loss of employees since June 2012, and the process is still underway. The dynamic of forecasts shows that enterprises basically no longer expect an increase in the number of employees.

Typically, it is the beginning of the year when the industry displays the highest hopes for a rise in the number of employees. In 2013, such hopes were able to hit just the zero balance of projections and steered the industrial sector, in mid-2013, to the greatest post-crisis shortage of workforce, with the proportion of responses about an insufficient number of employees having hit $22 \%$. In the period prior to the 2008 crisis, i.e. when the economy's heat-up was at its peak, the indicator would hit the level of $26-27 \%$. However, at the time, both the industrial sector, as well as the economy as a whole, displayed high growth rates and radiated selfconfidence, which generated a quite natural need in new labor force to meet the growing demand for industrial output. That said, with the industrial sector stagnating, the current shortage of cadres appears quite unnatural...

\section{Corporate Investment Plans}

It is for the second month in a row that corporate investment plans remained at their post-crisis lows. The domestic industrial sector has never been so pessimistic about investment since December 2009. As a reminder, back in the summer of 2011, the balance of the plans was +26 points, while currently it accounts for -14 points and the proportion of reports on the intent to cut back on investment was up $32 \%$ on a year-on-year basis. So, nearly one-third of the sector is going to reduce its investment activity in the end of the year, while authorities, on the contrary, trust in a bravura investment-wise ending of 2013.
EXPECTED CHANGES IN CAPITAL INVESTMENT ON

A YEAR-OVER YEAR BASIS (BALANCE=\% RISE -\% DECREASE)

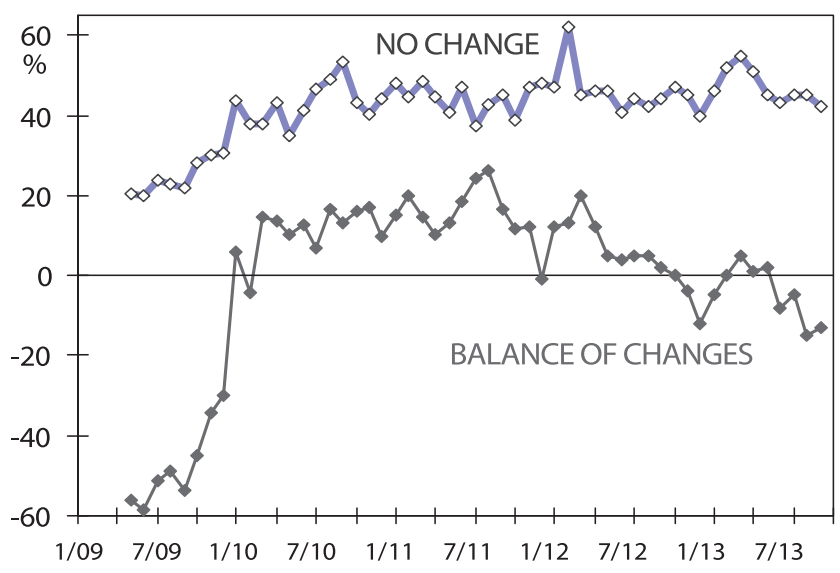

Fig. 6

There is nothing in the industrial sector's investment policy which may be construed as the unexpected. According to data of the IET's (anti-) crisis monitoring, the imperative to scale back on investment in a move to gear up for the crisis is appreciated by an increasing number of enterprises. While in 2012 the proportion of corporations planning to reduce their investment programs accounted for $20 \%$, the figure grew to $-24 \%$ in the early 2013, while in August 2013 already as many as $26 \%$ of corporations believed that such measures were appropriate. In the domestic industrial sector's list of anti-crisis measures this particular one proved second to cutting down costs and prices, and minimizing inventories. But the popularity of the top-of thelist measures appears just slightly different from the widespread of the cutting back on investment, with the search for more profitable suppliers (atop of the list) having steadily earned appreciation on the part of $32 \%$ of enterprises. 